\title{
Estudo Anatômico da Incidência do Canal Mesiopalatino em Primeiros Molares Superiores com Acesso Convencional ou Através de um Desgaste na Região de sua Embocadura
}

\section{Anatomical Study of the impact of canal orifice in maxillary first molars with access through conventional or wear one in the region of its mouth}

\author{
Mônica Viana dos Santos ${ }^{1}$ \\ Sylvio da Costa Júnior ${ }^{2}$ \\ Eduardo Meohas ${ }^{3}$ \\ Sergio Luiz Tavares Adriano ${ }^{4}$ \\ Gilberto Rocha Oliveira ${ }^{4}$ \\ Carlos Eduardo dos Santos Thuler ${ }^{5}$
}

\section{Palavras-chave: \\ Primeiro Molar \\ Superior Permanente}

Canal Mesiopalatino

Endodontia

\begin{abstract}
Resumo
O conhecimento da anatomia interna dos dentes humanos é essencial para se conseguir o sucesso na terapia endodôntica. O quarto canal conhecido como mesiopalatino em molares superiores, sempre foi motivo de discussão e polêmica. Foram analisados 50 primeiros molares superiores humanos, em que foi realizado o acesso convencional. Nos dentes em que não se constatou a presença do quarto canal, foi confeccionado um desgaste, na sua possível embocadura, e esses elementos foram então, novamente avaliados pelos Cirurgiões Dentistas. Após essa manobra, os dentes em que o quarto canal (mesiopalatino), mais uma vez, não foi observado por nenhum dos Cirurgiões Dentistas, tiveram a raiz mesiovestibular lixada, até a sua camada mais interna, com o objetivo de se constatar a presença ou não do quarto conduto. Com a tinta nanquim azul turquesa foi pintado o canal mesiovestibular e com o nanquim vermelho o canal mesiopalatino. O quarto canal mesiopalatino foi encontrado em 27 primeiros molares superiores (54\%) com acesso convencional, com desgaste na região de sua embocadura em 18 dentes $(36 \%)$, dos 5 dentes restantes que tiveram suas raízes lixadas, 4 não tinham o canal mesiopalatino $(8 \%)$, e apenas 1 desses dentes possuía o quarto canal (2\%). Pôde-se concluir que ocorreu uma elevada incidência da presença anatômica do quarto canal nas raízes mesiovestibulares dos primeiros molares superiores e que o desgaste na região de sua embocadura é essencial para se achar esse conduto e para que se tenha sucesso no tratamento endodôntico do primeiro molar superior permanente.
\end{abstract}

\section{Abstract}

The knowledge of the internal anatomy of human teeth is essential to achieve success in an endodontic therapy. The fourth duct known as orifice in maxillary molars is a source of discussion and controversy. 50 maxillary first molars were analyzed by the conventional approach. In the teeth which the presence of the fourth duct was not found a tear was done and these elements were re-evaluated by the dentists.
Key words:

First Permanent Molar

Canal Orifice

Endodontics 
After this maneuver, the teeth on the fourth duct (orifice) which were not observed by any dentists had their mesiobuccal root sanded up to their innermost layer with the aim to verify the presence or absence of the fourth conduit. The mesiobuccal duct was painted using turquoise Indian ink and the orifice duct was painted using red Indian ink. The fourth duct orifice was found in 27 first molars (54\%) with conventional access, 18 teeth (36\%) with tear in the region of its mouth, in the 5 other teeth that had their roots sanded, 4 didn't have the orifice duct (8\%) and only 1 of these teeth had the fourth duct (2\%). It can be concluded that there was a high incidence of anatomical presence of the fourth duct in mesiobuccal roots of the first maxillary molars, and the tear in the region of its mouth is essential to find this conduct and in order to have success in the endodontic treatment of the first permanent molar.

\section{Introdução}

O sistema de canais radiculares ainda é um mistério a ser desvendado, mesmo pelo bom endodontista, pois podem existir inúmeras variações anatômicas que precisam ser esclarecidas para que o clínico possa interpretar e desenvolver o seu papel adequadamente. O reconhecimento das variações anatômicas, seja em situações de normalidade ou não, permite menor incidência de insucessos e falhas durante os procedimentos endodônticos.

Um dos fatores essenciais para o sucesso clínico do tratamento endodôntico é o completo conhecimento da anatomia interna dos dentes, assim como das suas variações anatômicas.

Uma dessas variações que apresentam grande controvérsia na literatura, no que diz respeito a sua freqüência, e dada a sua importância clínica e envolvimento com as demais especialidades odontológicas, é o reconhecimento da presença do quarto canal nos primeiros molares superiores. Esse canal é chamado mesiopalatino e se encontra na raiz mesiovestibular desses elementos.

Há alguns anos, os clínicos e até mesmo os endodontistas acreditavam que os primeiros molares superiores apresentavam-se apenas com três canais, o que justifica o grande número de insucessos encontrados no tratamento endodôntico desses dentes.

Diante de tanta discussão, a avaliação da presença do quarto canal do primeiro molar superior permanente, é fundamental para o sucesso no tratamento endodôntico desses elementos.

\section{Método}

Foram selecionados 50 primeiros molares superiores humanos extraídos.

Os dentes foram colocados em vidro com hipoclorito de sódio a 2,5\% durante 6 horas para desinfecção.

$\mathrm{O}$ acesso foi realizado seguindo o formato convencional (segundo Pécora) com uma broca esférica $n^{\circ} 3$ e uma broca Endo $Z$, e então a câmara pulpar foi inundada com EDTA $17 \%$ por 5 minutos para limpar a câmara e facilitar o encontro do conduto. Após esse procedimento, a câmara foi lavada e seca com algodão. Em seguida, 5 Cirurgiões Dentistas, Clínicos Gerais observaram os dentes com auxílio de uma lupa e limas tipo K 08 e 10 (Maileffer). Nos dentes em que não se constatou a presença do quarto canal, foi confeccionado um desgaste, na sua possível embocadura, com a broca de baixa rotação $\mathrm{n}^{\circ} 0,5$ na tentativa de facilitar sua observação, e esses elementos foram então, novamente avaliados pelos Cirurgiões Dentistas. 

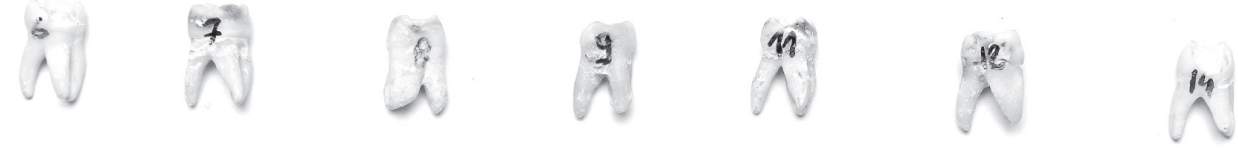

15

23

24

25

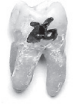

28

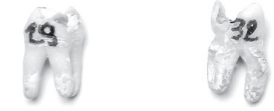

36
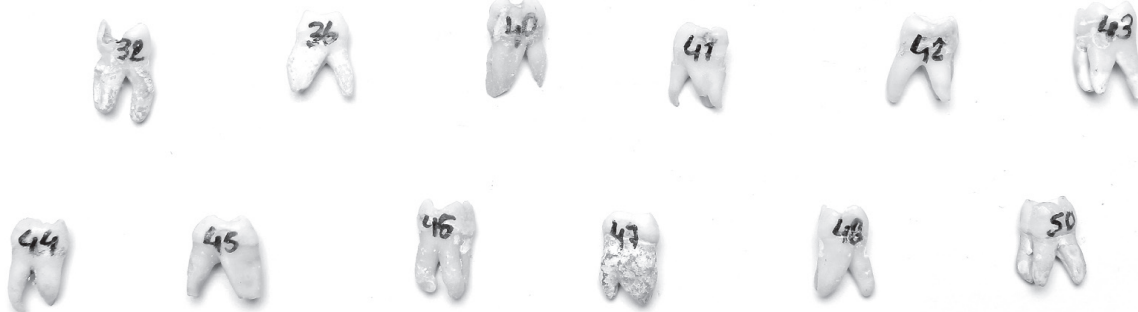

50

27 primeiros molares superiores onde o $4^{\circ}$ canal mesiopalatino foi encontrado através do acesso convencional

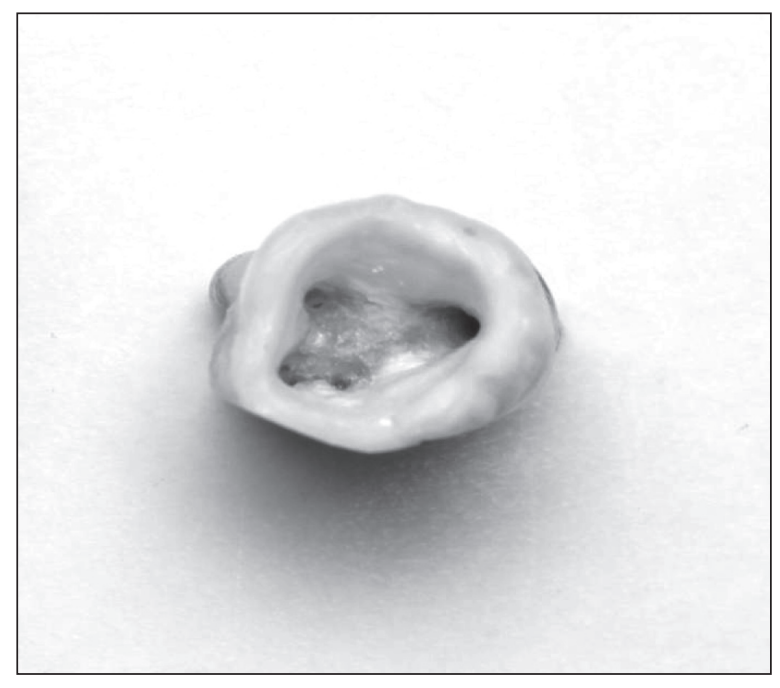

Desgaste realizado na região de embocadura
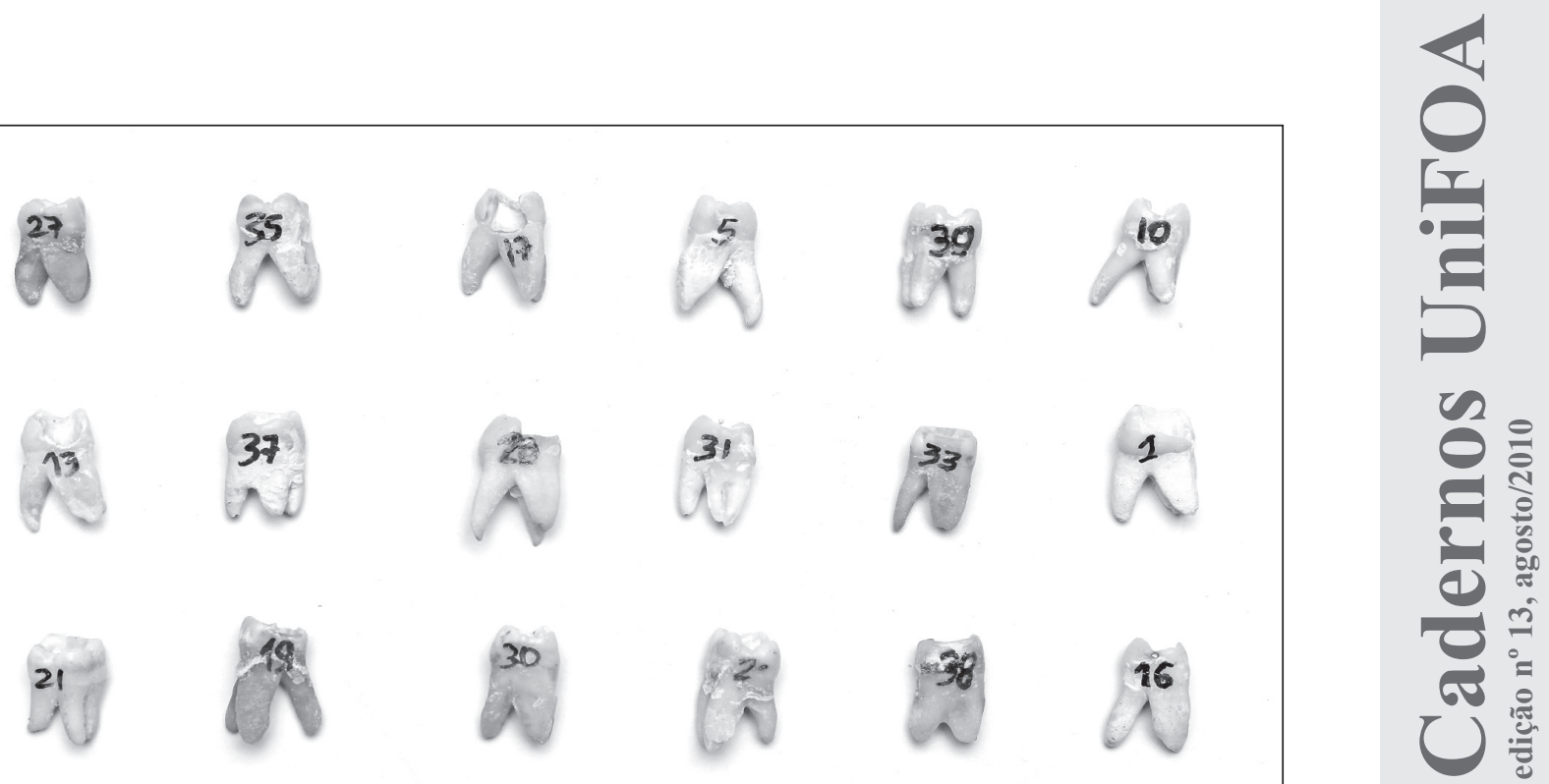

18 primeiros molares superiores onde o $4^{\circ}$ canal mesiopalatino foi encontrado através do desgaste na região de embocadura. 
Após essa manobra, os dentes em que o quarto canal (mesiopalatino), mais uma, vez não foi observado por nenhum dos Cirurgiões Dentistas, tiveram a raiz mesiovestibular lixa- da, primeiro com uma lixa de madeira e depois com uma lixa d’água, até sua camada mais interna, com o objetivo de constatarmos a presença ou não do quarto conduto.

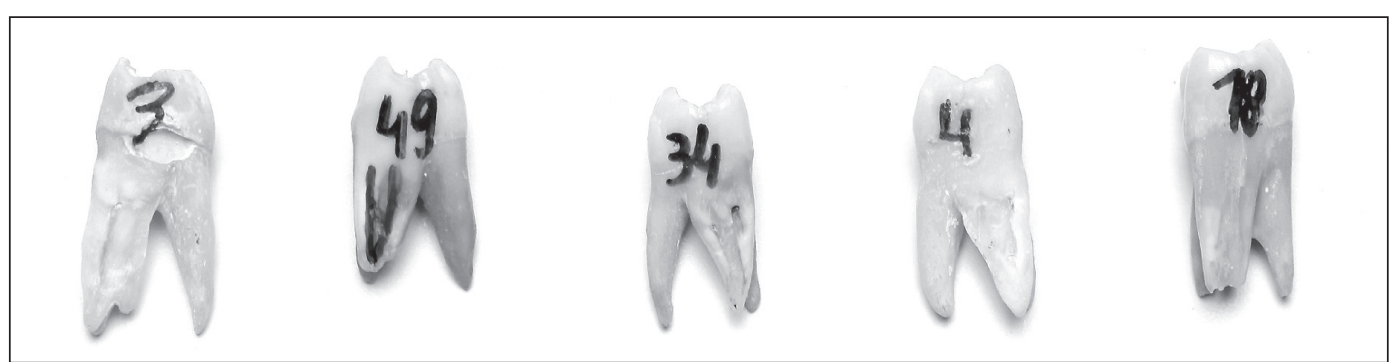

Os 5 primeiros molares restantes foram lixados e apenas 1 tinha o $4^{\circ}$ canal mesiopalatino

Com a tinta nanquim azul turquesa foi pintado o canal mesiovestibular e com o nanquim vermelho o canal mesiopalatino, para que pudessem ser observados de forma clara e distinta. Os condutos foram, então, fotografados.

\section{Resultados}

Dos 50 primeiros molares superiores estudados, o quarto canal mesiopalatino foi encontrado em 27 dentes com o acesso convencional.

Dos 23 dentes restantes em que o desgaste na região de embocadura foi realizado, o quarto canal mesiopalatino foi observado em 18 desses dentes.

Os 5 primeiros molares superiores que sobraram, em que não se localizou o quarto canal com acesso convencional, nem com o desgaste na região de embocadura, tiveram suas raízes lixadas e se constatou que apenas 1 desses tinha o quarto canal e os 4 dentes restantes não tinham o quarto canal mesiopalatino.

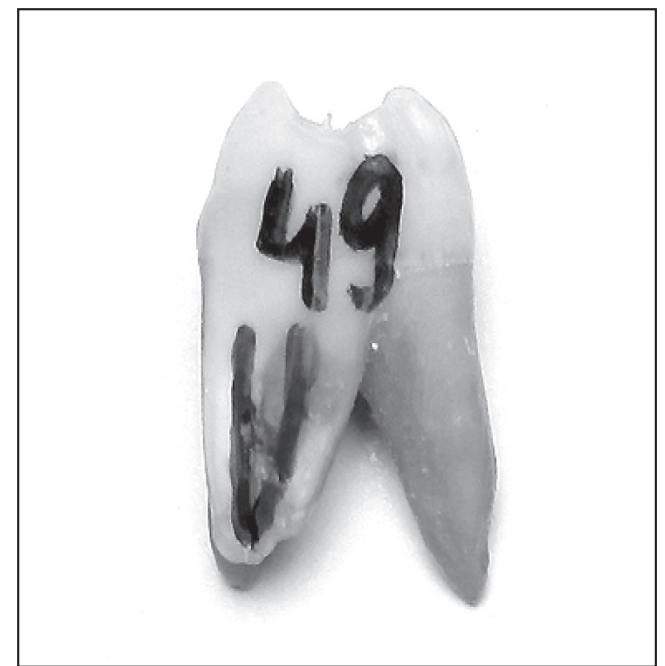

Dente que após ser lixado o $4^{\circ}$ canal mesiopalatino foi observado e então pintado com a tinta nanquim vermelho, e o canal mesiovestibular com a tinta nanquim azul turquesa

A tabela abaixo resume os resultados obtidos:

\begin{tabular}{|c|c|c|c|}
\hline Método de acesso & $\begin{array}{c}\text { Número de dentes } \\
\text { submetidos ao estudo }\end{array}$ & $\begin{array}{c}\text { Número de dentes nos quais o } \\
\text { quarto canal foi encontrado }\end{array}$ & Porcentagem \\
\hline Convencional & 50 & 27 & $54 \%$ \\
\hline $\begin{array}{c}\text { Desgaste na região } \\
\text { de embocadura }\end{array}$ & 23 & 18 & $78 \%$ \\
\hline Lixamento da raiz & 5 & 1 & $20 \%$ \\
\hline
\end{tabular}




\section{Análise de Resultados}

A cada dente da amostra foi atribuído um escore de acordo com a observação do quarto canal mesiopalatino:

1. Quarto canal observado mediante acesso convencional;

2. Quarto canal observado mediante desgaste na região de embocadura;

3. Quarto canal observado após o lixamento da raiz;

Aos dentes da amostra nos quais o quarto canal não foi observado, mesmo após os procedimentos descritos, foram atribuídos escore 0 .

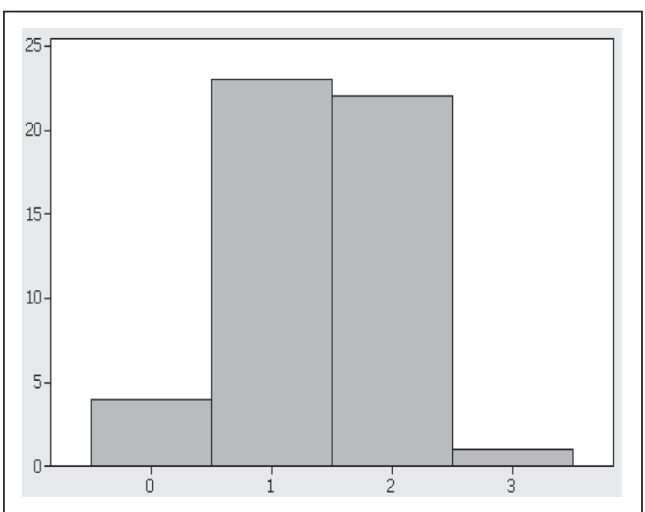

Gráfico 1 - Histograma de frequência dos escores obtidos.

Podemos constatar que:

- $\quad$ Em 54\% das amostras o quarto canal foi observado mediante acesso convencional.

- $\quad$ Em 36\% das amostras o quarto canal foi observado após o desgaste na região de embocadura.

- $\quad$ Em 2\% das amostras, o quarto canal somente foi observado mediante o lixamento da raiz.

- $\quad$ Em 8\% das amostras, o quarto canal não foi observado.

O gráfico a seguir indica as frequências relativas de cada escore obtido, de acordo com o procedimento, realizada para a observação do quarto canal.
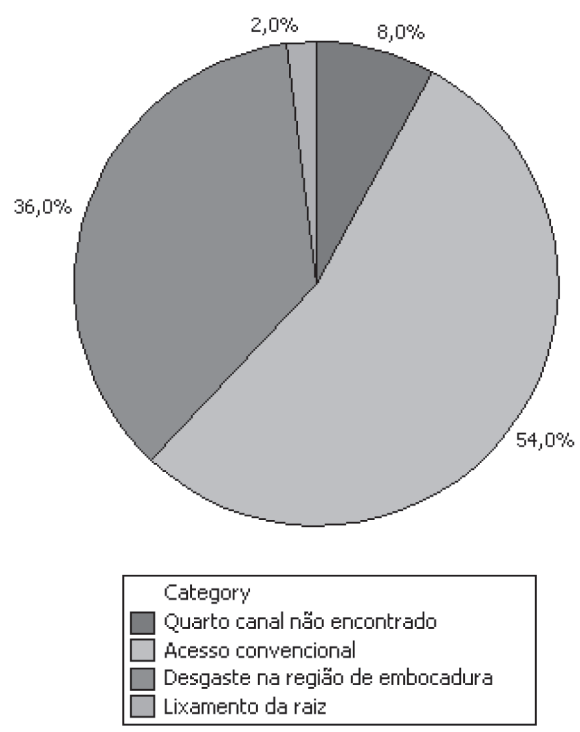

Gráfico 2 - Frequência relativa de escores.

Dos 23 dentes submetidos ao desgaste na região de embocadura, o quarto canal foi observado em $78 \%$ (18 dentes), enquanto que dos 5 dentes restantes submetidos ao lixamento da raiz, o quarto conduto foi observado em apenas um, ou seja, 20\%. Os gráficos abaixo fornecem uma análise comparativa de cada grupo:

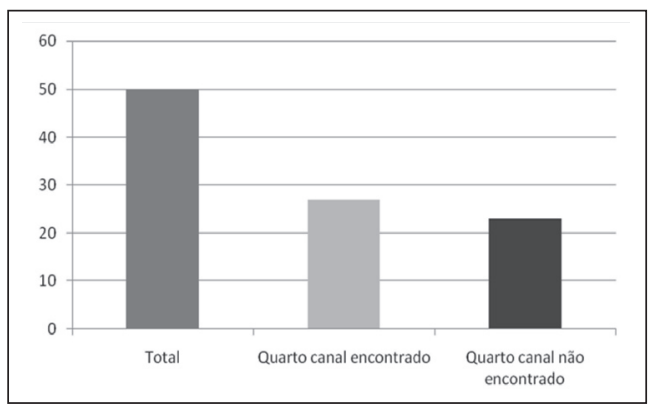

Gráfico 3 - Observação mediante acesso convencional.

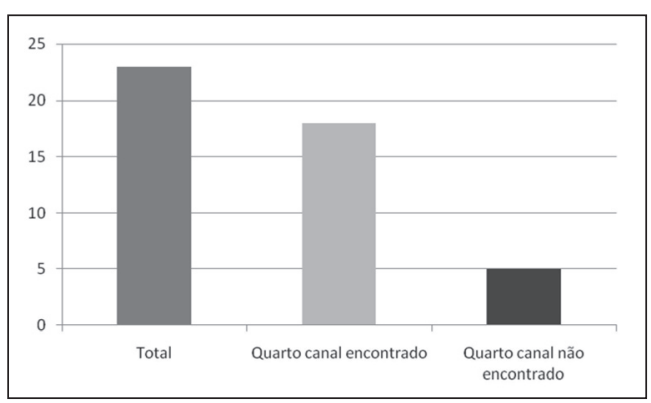

Gráfico 4 - Observação mediante desgaste na região de embocadura. 


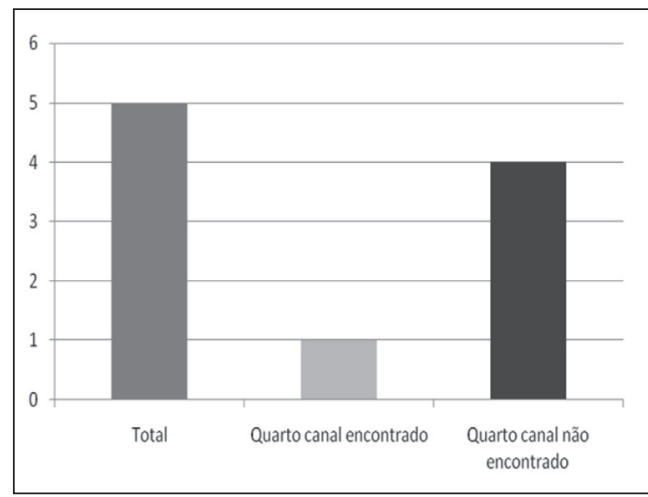

Gráfico 5 - Observação mediante lixamento da raiz.

Observou-se que a maior frequência relativa de dentes nos quais o quarto canal pôde ser encontrado ocorreu na amostra submetida ao desgaste na região de embocadura: $78 \%$ contra $22 \%$ nos quais o quarto canal não foi encontrado. $\mathrm{Na}$ amostra observada mediante acesso convencional, o quarto canal foi encontrado em 54\% dos dentes. O grupo submetido ao lixamento da raiz foi o único no qual a frequência relativa de dentes em que o quarto canal não pôde ser encontrado foi maior, $80 \%$ contra $20 \%$.

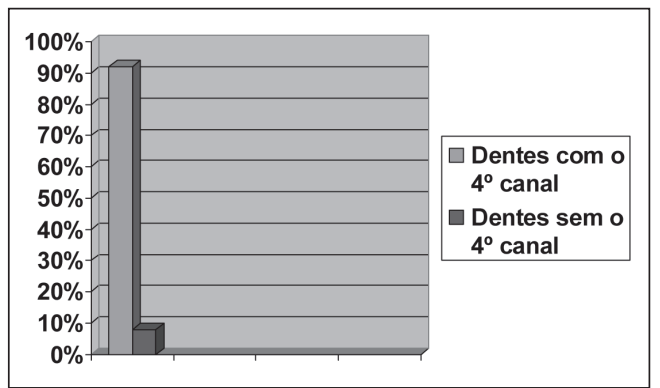

Gráfico 6 - Dos 50 dentes:

$92 \%$ tinham o $4^{\circ}$ canal e $8 \%$ não tinham o $4^{\circ}$ canal

\section{Discussão}

Para obtermos o sucesso no tratamento endodôntico, é necessário ter total conhecimento da anatomia dentária, principalmente em se tratando do primeiro molar superior que é considerado o maior dente em volume e o mais complexo do sistema de canais radiculares.

Por ser um dos dentes mais importantes na Endodontia, o primeiro molar superior tem sido indiscutivelmente um dos elementos mais pesquisados, e investigados, com o objetivo de aumentar o sucesso clínico no tratamento endodôntico (BURNS, R.; HERBRANSON, E.J., 2000).

Vários estudos já foram realizados para analisar a anatomia complexa do primeiro molar superior, principalmente da raiz mesiovestibu- lar, no intuito de se achar o quarto canal (mesiopalatino), mesmo assim, ainda se trata, indiscutivelmente, do dente posterior com maior índice de insucesso no tratamento endodôntico.

Dessa forma, julgamos pertinente fazer uma minuciosa avaliação da raiz mesiovestibular do primeiro molar superior, investigando assim a incidência do canal mesiopalatino nessa raiz que tem gerado mais pesquisas clínicas do que qualquer outro dente na boca.

Os trabalhos publicados na literatura apresentam uma variação nos índices da presença de 2 canais na raiz mesiovestibular. Essa discrepância pode ser explicada, em parte, levando-se em consideração o método de pesquisa utilizado. Os estudos in vivo relatam índices menores da presença do canal mesiopalatino pelas dificuldades em identificá-lo durante o ato operatório. Em contraposição, os estudos in vitro demonstram porcentagens maiores de incidência do canal mesiopalatino (SEIDBERG, B.H., 1973).

Vários são os trabalhos e relatos de casos clínicos encontrados na literatura que descrevem o grande auxílio que nos traz a utilização do Microscópio Operatório. Antigamente, o segundo canal mesiopalatino situado na raiz mesiovestibular dos primeiros molares superiores, tinha uma incidência pouco relevante quando comparada a que é dita atualmente. Em busca da qualidade do tratamento endodôntico, o Microscópio Operatório surge com a finalidade de reduzir alguns obstáculos encontrados pelos endodontistas (COUTINHO, F., 2006) (FOGEL, H.M., 1994) (FONTANA, C.E.; BUENO, C.E.S; CUNHA, R.S., 2004).

O Microscópio Operatório vem revolucionando a maneira como os procedimentos são efetuados e também atualizando os vários conceitos que circundam o dia-a-dia clínico da Endodontia, principalmente por proporcionar uma magnitude visual ao tratamento. Mesmo assim, em muitos casos, essa visualização não será possível, necessitando, então, que o profissional tenha um conhecimento singular da anatomia. Essa afirmação está de acordo com muitos autores, que fizeram uso do Microscópio Operatório em suas pesquisas, e constataram sua importância ao tentar localizar o canal mesiopalatino nos primeiros molares superiores (COUTINHO, F., 2006) (FOGEL, H.M., 1994) (FONTANA, C.E.; BUENO, C.E.S; CUNHA, R.S., 2004). 
No que diz respeito ao custo, esse equipamento ainda possui um preço relativamente alto, tornando-se inacessível para maioria dos profissionais da Odontologia. Por isso, julgamos esse trabalho totalmente importante para Endodontia, pois apesar de todos os benefícios que o Microscópio Operatório nos oferece ele ainda está longe da realidade da maioria dos profissionais da Odontologia. Dessa forma, voltamos a afirmar a necessidade do conhecimento da anatomia dental interna e também de outros recursos como o desgaste na região de embocadura, aqui proposto para se obter o sucesso no tratamento endodôntico desses dentes.

Queremos destacar, nesse momento, outro estudo realizado utilizando tambémo Microscópio Operatório, que comparou a incidência do quarto canal mesiopalatino na raiz mesiovestibular dos primeiros e segundos molares superiores, onde estatisticamente essa diferença não foi significativa, porque a metodologia empregada nesse estudo não analisou todos os dentes com o Microscópio Operatório e sim de apenas uma pequena parte, isso explica o baixo índice do quarto canal localizado com o auxílio do Microscópio Operatório, além disso esse trabalho também não explica que tipo de acesso foi realizado no experimento (KULILD, J. C., 1990).

Em outra pesquisa, o número de primeiros molares que tinham o segundo canal mesiopalatino foi extremamente baixo, o que nos faz desconfiar da metodologia empregada, pois a quantidade de primeiros, segundos e terceiros molares que foram utilizados nessa pesquisa não foi revelada. E está mais do que evidente na literatura, que o índice do quarto canal nos primeiros molares superiores é bem maior do que foi achado nesse estudo (RODRIGUES, D. L., 2004).

Além dessas metodologias, outros estudos foram realizados, em que através da técnica radiográfica e da diafanização, analisaram a morfologia e anatomia dos primeiros molares superiores, conseguindo como resultado um alto índice da presença do canal mesiopalatino.

Tais resultados estão em concordância com outros autores, que afirmaram que a técnica de diafanização favorece a detecção e detalhes anatômicos com mais acuidade que outras técnicas, pois confere transparência aos dentes estudados, além de preservar a sua forma anatômica original e permitir uma visão tridimensional do elemento dentário (COELHO, C. S. M., 2004).
Optamos neste trabalho por fazer um experimento realizando um desgaste na região de embocadura dos primeiros molares superiores permanentes, em que se avaliou a importância que esse desgaste proporciona na localização do quarto canal na raiz mesiovestibular dos primeiros molares superiores permanentes. Essa metodologia é semelhante a empregada por outros autores.

A modificação no acesso endodôntico dos primeiros molares superiores permanentes analisados neste estudo, não só aumenta o número de canais localizados, como também facilita a visualização e entrada dos instrumentos endodônticos nesses dentes. Essa modificação deve ser incorporada na fase do acesso endodôntico de todos os molares superiores sujeitos ao tratamento endodôntico.

A experiência do operador na tentativa de se localizar o quarto canal mesiopalatino também é fundamental para se ter sucesso no tratamento endodôntico dos primeiros molares superiores. Essa afirmação corrobora com outro estudo realizado, que utilizou uma metodologia que levou 8 anos para ser concluída, e constatou que com um operador mais experiente a chance de se achar o canal mesiopalatino é bem maior do que quando não se tem experiência (JOHN, J; STROPKO, D. D. S, 1999).

No presente estudo a incidência do quarto canal foi bastante significativa, o que nos leva a fazer uma análise cada vez mais cuidadosa desse elemento dentário tão complexo que é o primeiro molar superior permanente, e de sua raiz mesiovestibular.

Este estudo é discordante de outro trabalho, onde a incidência do canal mesiopalatino foi de $37 \%$ do total de amostras investigadas, índice extremamente baixo, apesar de o autor desse experimento considerar uma incidência significativa.

Vários experimentos encontraram a prevalência de 2 condutos sobre 1 único, na raiz mesiovestibular dos primeiros molares superiores, entretanto, outros estudos demonstram índices menores em suas pesquisas (COELHO, C. S. M., 2004) (FOGEL, H. M, 1994) (KULILD, J. C, 1990).

Um estudo utilizando somente a análise radiográfica na busca do canal mesiopalatino em primeiros molares superiores, mostrou um baixo índice desses canais, o que evidentemente 
foi determinado pela falha na metodologia, em que o autor não fez uso de outros recursos na sua pesquisa como o Microscópio Operatório.

Tal resultado está em concordância com outra pesquisa, que obteve uma taxa percentual baixa ao analisar radiograficamente a trajetória do quarto canal no primeiro molar superior.

Uma outra metodologia empregada demonstra a dificuldade de se localizar o canal mesiopalatino quando se realiza um estudo in vivo, isso se dá, evidentemente, pela falta de habilidade e de conhecimento anatômico do operador.

Alguns autores utilizaram outros meios para se achar o quarto canal nos primeiros molares superiores, através do cateterismo exploratório determinando a frequência desse conduto.

Analisando os trabalhos de cada autor estudado, parece-nos claro afirmar que a experiência do operador ao realizar o acesso endodôntico do primeiro molar superior é fundamental para se obter êxito no tratamento endodôntico do mesmo, e que o uso do Microscópio Operatório ajuda e muito o sucesso da terapia endodôntica. No estudo do caso clínico de um primeiro molar superior, observou-se a presença de um terceiro canal na raiz mesiovestibular, o que só foi possível pela habilidade e conhecimento anatômico do operador, este trabalho nos mostra, mais uma vez, a importância da experiência e do conhecimento do operador na terapia endodôntica.

Todavia, apesar da alta taxa de sucesso alcançado nos tratamentos endodônticos, a raiz mesiovestibular ainda está associada a um número considerável de fracassos, devido à dificuldade de se empregar uma técnica adequada para se achar o quarto canal mesiopalatino.

No trabalho em que as raízes dos primeiros molares superiores foram cortadas e tingidas, encontrou-se, também, uma elevada porcentagem do quarto canal nesses dentes. Tal resultado demonstra, mais uma vez, que os estudos realizados no laboratório da raiz mesiovestibular, o índice de achados do canal mesiopalatino são superiores aos dos estudos in vivo.

O conhecimento da anatomia interna dos dentes é de fundamental importância para a realização correta do tratamento endodôntico e vários são os erros cometidos pela falta do conhecimento anatômico. Esses argumentos justificam estudos anatômicos desses elementos.

Fazendo uma análise global do tema desse estudo, fica claro que a considerável va- riação na incidência do canal mesiopalatino, deve-se, principalmente, às diversas metodologias empregadas e também à seleção das amostras pesquisadas.

Cada vez mais novos estudos devem ser realizados em busca da presença do quarto canal mesiopalatino nos primeiros molares superiores, pois alguns resultados são ainda bastante conflitantes, apesar de toda a tecnologia hoje disponível.

\section{Conclusão}

Diante do exposto e dentro das condições estabelecidas para o experimento, é lícito concluir que:

- Ocorreu uma elevada incidência da presença anatômica do quarto canal nas raízes mesiovestibulares dos primeiros molares superiores.

- O desgaste na região de sua embocadura é essencial para se achar o quarto canal (mesiopalatino) que se encontra na raiz mesiovestibular dos primeiros molares superiores permanentes.

- $\quad$ Esse desgaste fez o índice de localização de canais subir de $54 \%$ para $90 \%$.

- $\quad$ Apenas 2\% dos canais não foram localizados com o desgaste na região de embocadura.

\section{Referências Bibliográficas}

1. ABUXAPQUI, F. et al. Frecuencia del segundo conducto em la raiz mesiovestibular del primer molar superior em pacientes de la ciudad de Mérida, Yucatán, México. Rev. ADM; 54(3):131-3, MAYO-JUN. 1997.

2. ALCOTA, M.R.; MEDINA, L.B. Ocurrencia del cuarto conducto em primeros molares superiores permanentes. Odontol. Chil; 46(1):9-11, dic. Ilus, tab. 1998.

3. BUHRLEY, L.J. et al. Effect of magnification on locating the MB2 canal in maxillary molars. Printed in U.S.A. Vol. 28, No. 4. 2002. 
4. BURNS, R.; HERBRANSON, E.J. Morfologia dentária e cavidades de acesso. In: COHEN, Stephen; BURNS, Richard. Caminhos da Polpa. Rio de Janeiro, RJ: Guanabara Koogan, 2000. p.140-190.

5. COELHO, C.S.M. et al. Configuração anatômica interna da raiz mésiovestibular de primeiros molares superiores permanentes. Guia Odonto. 2004.

6. COUTINHO, F. et al. Influência do microscópio cirúrgico na localização do canal mesiopalatino: uma análise laboratorial. Braz. oral res. [online]. v. 20, n.1, pp. 59-63. ISSN 1806-8324, 2006.

7. FAVIERI, A. et al. Root canal therapy of a maxillary first molar with five root canals: case report. Braz. Dent. J. vol. 17 n. 1 Ribeirão Preto 2006.

8. FERREIRA, P.O.M. et al. Análise radiográfica da trajetória do quarto canal no primeiro molar superior. RSBO v. 4, n. 2, p. 12-15, 2007.

9. FOGEL, H.M.. et al. Configuração da raiz mesiovestibular do primeiro molar superior: um estudo clínico. J. Endod. 1994 MAR; 20 (3) :135-7.

10. FONTANA, C.E.; BUENO, C.E.S; CUNHA, R.S. Microscópio Cirúrgico: a importância da magnificação visual e aumento da luminosidade em Endodontia. Jornal do Site. JULHO (2004).

11. GIILES, J. et al. Uma investigação do canal mesiopalatino em molares superiores e molares inferiores. Oral Surg Oral Méd Oral Pathol. 1990 NOV. 70 (5) : 638-43.

12. JOHN, J; STROPKO, D.D.S. A morfologia dos canais dos molares superiores: observações clínicas das configurações dos canais. J. Endod. 1999 JUNHO; 25 (6) : 446-50.

13. KULILD, J.C. et al. Incidence and configuration of canal systems in the mesiobuccal Root of maxillary first and second molars. Printed in U.S.A. Vol. 16, No 7. JULY 1990.
14. MANCILHA, F.A.B. et al. Estudo comparativo da anatomia interna de dentes anômalos pelos métodos radiográfico e diafanização. SOTAU R. virtual Odontol - Vol 5 Ano 2 - 2007.

15. MURTA, P.R.O.; MORDENTE, V.L.M. A polêmica do quarto canal. Correio ABO - JANEIRO/2005: 18-19.

16. PÉCORA, J.D. et al. Morphologic study of the maxillary molars part II; Internal anatomy. Braz. Dent. J. (1992) 3 : 53-57.

17. RODRIGUES, D.L. et al. Estudo anatômico da incidência do canal mesiopalatino em raízes mesiovestibulares de molares superiores. J. Bras. Endodond 2004; 5 (19): 316

18. SAAD, A.N. A prevalência de dois canais na raiz mesial de primeiros molares superiores permanentes tratados endodonticamente na sub-população da Arábia Saudita. Dental Journal 2005; 17 (1): 24-28.

19. SAVIOLI, R.N. et al. Influência do acesso endodôntico na localização dos canais radiculares dos molares superiores. ROBRAC, 6(20), 1996.

20. SEIDBERG, B.H. et al. Frequency of two mesiobuccal root canals in maxillary permanent first molars. J. AM. DENT. ASSOC. 1973. Vol. 87. : 852- 55.

21. THOMAS, R.P.; MOULE, A.J.;BRYANT, R. Morfologia do canal radicular dos primeiros molares superiores permanentes em diferentes idades. Int Endod. J. 1993 SEP; 26 (5) : 257-67.

22. WELLER, N.R. et al. A importância da localização e preenchimento do istmo do canal radicular em múltiplos sistemas. Um estudo de Microscopia Cirúrgica da raiz mesiovestibular do primeiro molar superior permanente. Printed in. U.S.A. Vol 21, No. 7. JULY 1995.

\section{Endereço para Correspondência:}

Sylvio da Costa Júnior

sylviocosta13@hotmail.com

Rua Narcisa Amália 167 - Santa Cecília

Resende - RJ

CEP:27520100 